\title{
Characteristics of Impulse Carburization LPC Process
}

\author{
Ryszard Filip *(D), Kamil Ochał, Kamil Gancarczyk, Wojciech Jerzy Nowak (D), Barbara Kościelniak (D) \\ and Bartek Wierzba
}

Citation: Filip, R.; Ochał, K.; Gancarczyk, K.; Nowak, W.J.;

Kościelniak, B.; Wierzba, B

Characteristics of Impulse

Carburization LPC Process. Materials

2021, 14, 4269. https://doi.org/

$10.3390 / \mathrm{ma} 14154269$

Academic Editors: Giovanni Bruno and Tetsuo Shoji

Received: 18 May 2021

Accepted: 29 July 2021

Published: 30 July 2021

Publisher's Note: MDPI stays neutral with regard to jurisdictional claims in published maps and institutional affiliations.

Department of Materials Science, Faculty of Mechanical Engineering and Aeronautics, Rzeszow University of Technology, Powstancow Warszawy 12, 35-959 Rzeszow, Poland; kochal@prz.edu.pl (K.O.); KamilGancarczyk@prz.edu.pl (K.G.); wjnowak@prz.edu.pl (W.J.N.); b.koscielnia@prz.edu.pl (B.K.); bwierzba@prz.edu.pl (B.W.)

* Correspondence: ryfil@prz.edu.pl; Tel.: +48-17-8651144

\begin{abstract}
In the present work, Pyrowear53 steel was subjected to the impulse carburizing LPC process. After carburation, the material was quenched and tempered. Postprocessing analyses included the measurement of hardness, carbon content, residual austenite, and residual stresses. The results revealed that the thermochemical treatment resulted in the formation of an approximately $1200 \mu \mathrm{m}$ wide carburized layer. The results of hardness, carbon content, and residual austenite measurement showed a continuous gradient (drop) in the measured values within the carburized layer. However, the results of residual stresses revealed the existence of a local extremum, namely, a zone with higher compressive stresses at the depth between 600 and $1000 \mu \mathrm{m}$. This was explained by a different temperature for initiation of martensite transformation as a function of carbon content. This difference resulted in the occurrence of two martensite expansion fronts at two different depths, resulting in an increase in compressive stresses at the noted depth range. Moreover, it was concluded that this region was present for material containing between 0.8 and $0.4 \mathrm{wt} \%$ carbon for Pyrowear 53 .
\end{abstract}

Keywords: low-pressure carburizing; Pyrowear53; hardness; residual stresses; carbon concentration

\section{Introduction}

Carburizing and hardening processes are the most important processes in the materials economy. Almost all of the existing devices include gears or other hardened components. These gears are treated first by the carburizing process and then hardened in oil, soles, nitrogen gas, or other media. The carburizing temperature varies from 870 to $940{ }^{\circ} \mathrm{C}$; the gas atmosphere for carburizing is produced from liquid or gaseous hydrocarbons such as propane, butane, or methane [1,2]. The study of process parameters in metals during heat treatment has been of considerable interest for some years [3-6], but there has been relatively little work on process variables during the surface hardening process [7] since controlling parameters in carburizing is a complex problem. The major influencing parameters in carburizing are holding time, carburizing temperature, carbon potential, and quench time in oil [8].

Heavy-duty gearboxes used in aviation are usually made of high-strength alloy steels such as AMS 6308D. In this paper, the influence of the cyclic carburizing process in low pressure carburizing of Pyrowear53 steel on the diffusion process is discussed.

The chemical composition of Pyrowear53 is presented in Table $1[9,10]$. The measured contents of the elements in Pyrowear53 are in accordance with the nominal composition of AMS 6308D.

In the past, Pyrowear53 steel was studied in terms of carburization. A few attempts at modeling the low-pressure carburization process have also been conducted. It was shown that good concurrence between modeled and measured values of distortion and residual stress can be achieved using simulation with the commercial finite-element-based package-DANTE $[11,12]$. However, most of the literature manuscripts deal with the 
determination of the carburization recipe to find the proper carbon layer. The basic idea is to develop the proper simulation model. These models are based on diffusion phenomena and proper determination of the diffusion flux of carbon during the process. Such models allow for determination the number of carbon and diffusion cycles during the process and allow for controlling the number of carbides generated during carburization. The model describing carburization of multicomponent alloys was proposed by Bongartz et al.; their work was based on the second Fick law with a composition-dependent diffusion coefficient [13-15]. Modeling of the carburization process, when the local equilibrium condition holds, implies the compact carbon layer formation. Therefore, models involving this factor are based on the diffusion equation and the Wagner model [16-21].

Table 1. Nominal chemical composition of AMS 6308D and composition of Pyrowear53 steel measured using Spark-OES, wt $\%$.

\begin{tabular}{|c|c|c|c|c|c|c|c|c|c|c|c|}
\hline Element & $\mathrm{Fe}$ & C & Mn & $\mathrm{Si}$ & $\mathbf{P}$ & $\mathrm{s}$ & $\mathrm{Cr}$ & $\mathrm{Ni}$ & Mo & $\mathrm{Cu}$ & V \\
\hline Nominal (wt\%) & Bal. * & $0.07-0.13$ & $0.25-0.50$ & $0.60-1.20$ & $<0.015$ & $<0.010$ & $0.75-1.25$ & $1.60-2.40$ & $3.00-3.50$ & $1.80-2.30$ & $0.05-0.15$ \\
\hline Measured (wt \%) & Bal. * & 0.13 & 0.41 & 0.93 & 0.011 & 0.003 & 1.04 & 1.97 & 3.23 & 1.92 & 0.1 \\
\hline
\end{tabular}

The aim of this work is to present the influence of carbon cyclic diffusion and the subsequent oil hardening process on the microstructure and residual stress depth profiles. Thus, the experimental results of carbon concentration, hardness, residual austenite, and stress as a function of distance are presented. This process was previously modeled using the bivelocity method. The detailed description can be found elsewhere [22].

\section{Materials and Methods}

In this paper, the rectangular cube shape samples with dimensions $20 \times 20 \times 10 \mathrm{~mm}^{3}$ were prepared from the Pyrowear53 steel. The samples were inserted into a vacuum furnace in order to carburize. They were carburized, quenched, and tempered. The temperature for carburizing was $925^{\circ} \mathrm{C}$. After carburizing, the samples were austenitized at the temperature of $910^{\circ} \mathrm{C}$ and quenched in oil. The subzero treatment was performed after quenching. The tempering was performed at the temperature of $200{ }^{\circ} \mathrm{C}$ in nitrogen gas atmosphere. Saturation and diffusion times for carburizing were computed using numerical simulation of the mass diffusion mathematic model based on the Darken approximation [3]. The vacuum carburizing followed by quenching and tempering was carried out to achieve a $0.9-1.2 \mathrm{~mm}$ effective case depth. The carburized case depth was measured with the use of an Innovatest Nexus 4000 microhardness tester (INNOVATEST, Maastricht, The Netherlands) with Vickers indenter HV 0.5 (INNOVATEST), and GD-OES depth profiling (Horiba Jobin Yvon, Paris, France). Elastic deformation and retained austenite were determined using a Proto iXRD COMBO portable diffractometer (Proto Mfg. Ltd., Oldcastle, ON, Canada). For the measurement of residual stresses as a function of depth, the electrolytic polishing method was used with a step of $100 \mu \mathrm{m}$ using a Proto Manufacturing Electriolithic 8818 -V3 polisher (Proto Mfg. Ltd.). To calculate internal stresses, the sin $2 \psi$ method [23] was applied with the assistance of Win2.0 XRD software. The $\sin 2 \psi$ method is based on the Bragg-Brentano symmetrical diffraction and the appropriate elastic constants, and uses a $\Psi$-type goniometer, which allows for obtaining appropriate inclinations of the diffraction vector by $\Psi$ angles in a plane perpendicular to the diffraction plane [24]. A lamp with a chrome anode of characteristic $\mathrm{Cr} \mathrm{K} \alpha$ radiation of $0.2291 \mathrm{~nm}$ wavelength was used due to the radiation source of $20 \mathrm{kV}, 4 \mathrm{~mA}$ with a beam diameter of $2 \mathrm{~mm}$. The effective depth of X-ray beam penetration was $5 \mu \mathrm{m}$. The measurement was taken on the surface of the specimen. After the measurement, the surface was electropolished for the removal of $100 \mu \mathrm{m}$ of the material and the measurement repeated. By this procedure, a plot of measured residual stresses as a function of depth with the step of $100 \mu \mathrm{m}$ was produced. Residual stresses were determined for constant values of $\Psi$ angle in the range from $25^{\circ}$ to $-25^{\circ}$. The diffraction line $\{211\}$ of martensite phase was analyzed for residual stresses in the subsurface region. In the measurement of residual stresses, the values of $\mathrm{X}$-ray elastic constant used for calculations were ${ }^{1} /{ }_{2} S_{2}=5.8 \times 10^{-6} \mathrm{MPa}$ and $-\mathrm{S}_{1}=1.34 \times 10^{-6} \mathrm{MPa}$. 
The quantity of retained austenite was measured for diffraction lines $\{200\},\{211\}$ of martensite and $\{220\},\{200\}$ of austenite phases. After heat treatment and standard procedure for preparation of metallographic cross-sections, the samples were examined using a Hitachi S3400 N scanning electron microscope (Hitachi, Tokyo, Japan) coupled with an energy dispersive spectrometer (EDS). Images were captured in the back-scattered electron (BSE) mode, which enabled the increase of the contrast between the phases. The chemical composition of the phases present in the carburized material was measured using EDS. The dimensions of the phases identified were determined using the NIS-Elements software based on SEM/BSE images. The depth profiles of the samples after the carburizing process were performed using a Horiba JobinYvon glow discharge optical emission spectrometer (GD-OES). The GD-OES depth profiles were quantified using the procedure described in [25-27].

\section{Results}

The microstructure of the cross-section of a carburized sample is presented in Figure 1. The microscopic examination showed the presence of massive and globular carbides at the surface of the steel substrate and the presence of fine carbides inside the carburized layer, which was high-carbon martensite. The formation of massive carbide precipitates indicates that the steel was supersaturated with carbon in the subsurface area (Surface). The presence of fine carbides inside and at the boundaries of austenite grains was also observed (depth of 200 and $400 \mu \mathrm{m}$ ). The microstructure in the sample core was tempered martensite with uniformly dispersed alloy carbides containing mainly molybdenum (depth of $800 \mu \mathrm{m}$ ). Residual austenite was present in amounts that cannot be estimated with a light or scanning microscope.

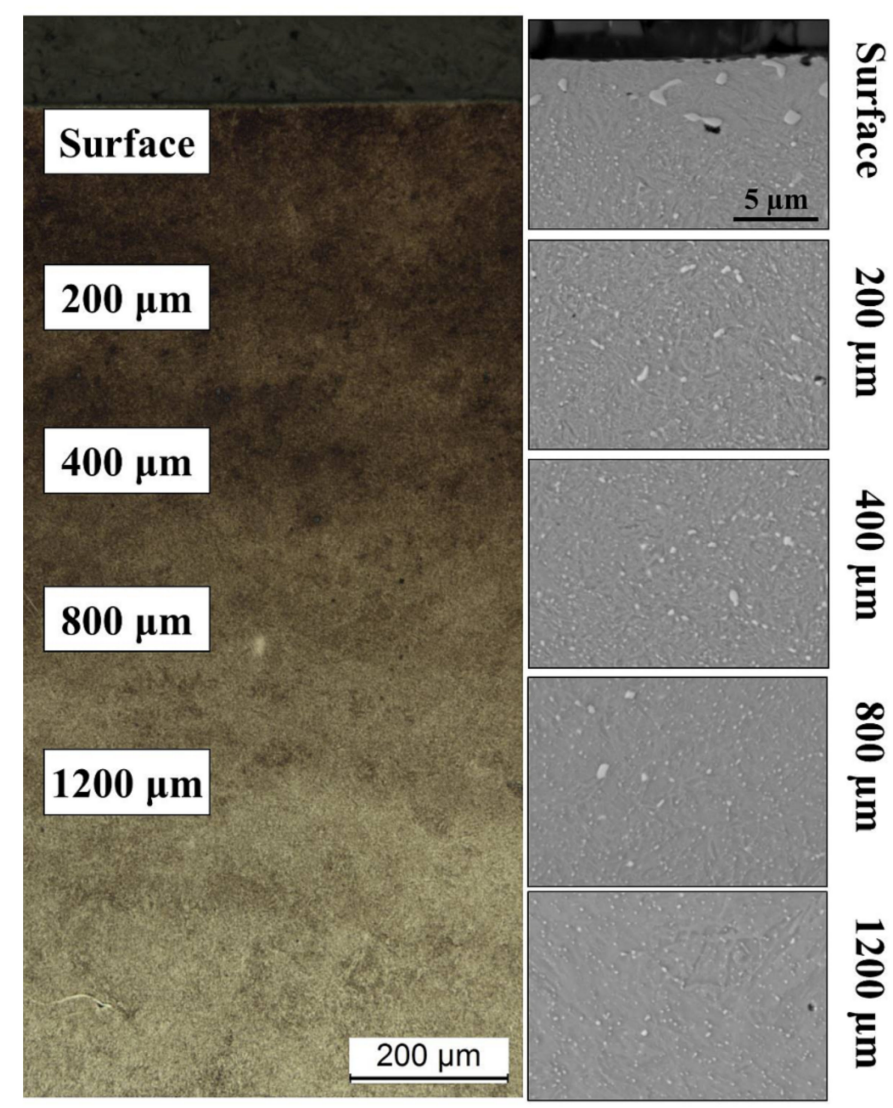

Figure 1. Microstructure of carburized Pyrower53 observed using an optical microscope (left) and magnifications observed at given depth using a scanning electron microscope (right). 
After the low pressure carburizing process, hardness, carbon concentration profile, residual austenite, and stresses as a function of distance were measured. The hardness profile is typical for carburized steel. The profile starts with the plateau and hardness decreases with the distance from the surface of the sample. The highest hardness value was obtained in the subsurface region (up to $300 \mu \mathrm{m}$, Figure 2) of the sample. The maximum value of hardness in this region was approximately $780 \mathrm{HV}$, whereas the lowest was measured at the core of the sample, approximately $1300 \mu \mathrm{m}$, and the value was about $350 \mathrm{HV}$. The hardness profile of Pyrower53 steel after the cyclic carburizing process is presented in Figure 2. A similar hardness profile on carburized Pyrowear53 was obtained by A. Wojtyczka and B. Iżowski [20]. Moreover, the measured values of hardness are in very good agreement with those modeled using Equation (1).

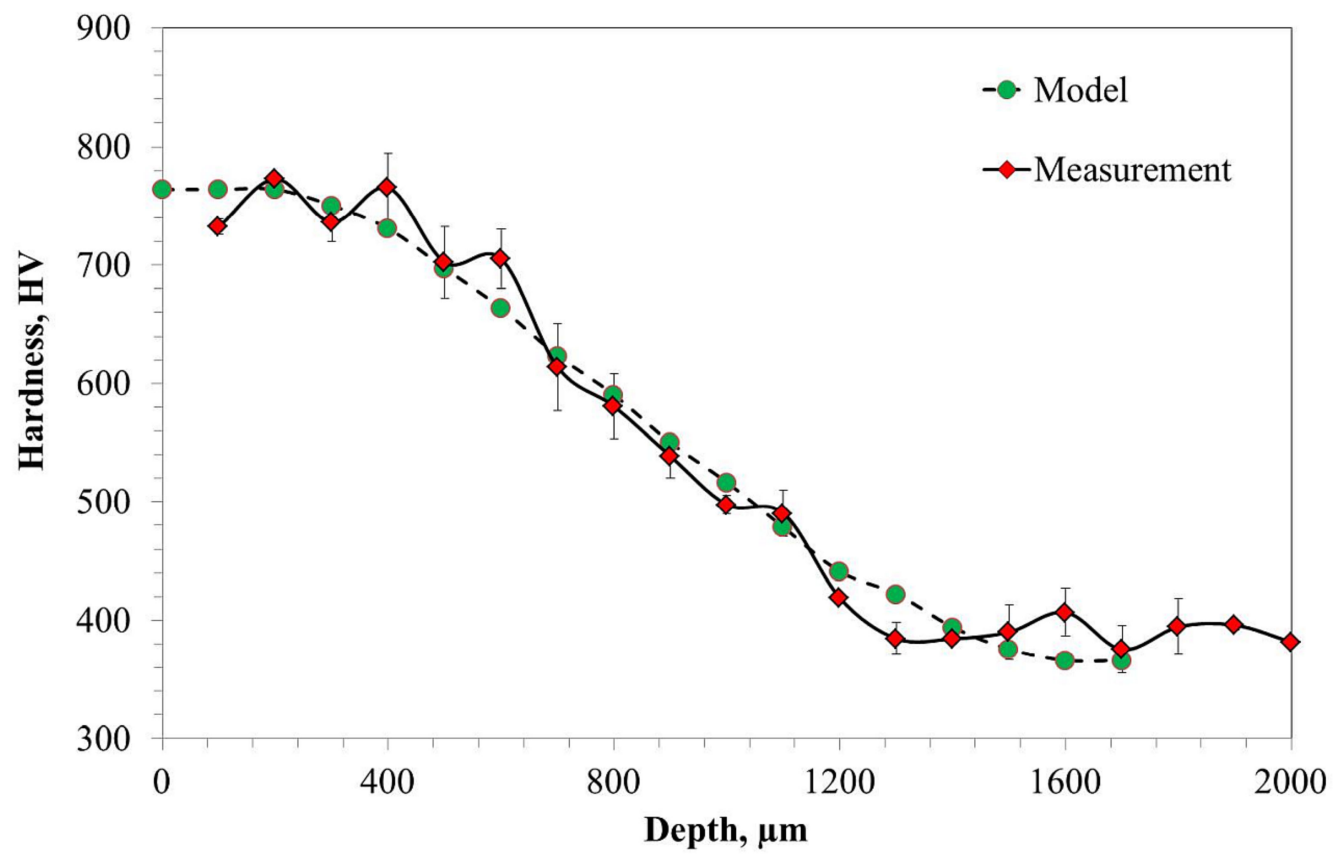

Figure 2. Profile of measured and modeled hardness of Pyrower53 steel after cyclic carburizing process.

Along with hardness measurement, the GD-OES concentration profile as a function of depth was performed. As demonstrated in the GD-OES depth profile shown in Figure 3, the highest carbon concentration was measured in the subsurface region of the sample up to approximately $400 \mu \mathrm{m}$, where the carbon concentration is $1 \mathrm{wt} \%$; the carbon concentration then decreased with depth. The lowest concentration was observed at the depth of $1500 \mu \mathrm{m}$ and equal to $0.2 \mathrm{wt} \%$. This value is very close to the initial concentration of carbon in the Pyrower53 steel, Figure 3.

During the hardening process, austenite transforms into martensite. However, during this phase transformation some residual austenite remains in the alloy's microstructure. This residual austenite content should decrease with decrease of carbon content. The experimental and modeled (using Equation (2)) results of residual austenite content are shown in Figure 4. At the surface, the residual austenite content is the highest and decreases with depth and carbon concentration. The highest value at the surface is $7.5 \mathrm{wt} \%$, and at the core residual austenite is $3.2 \mathrm{wt} \%$. As can be observed, the measured and modeled values are in good agreement. 


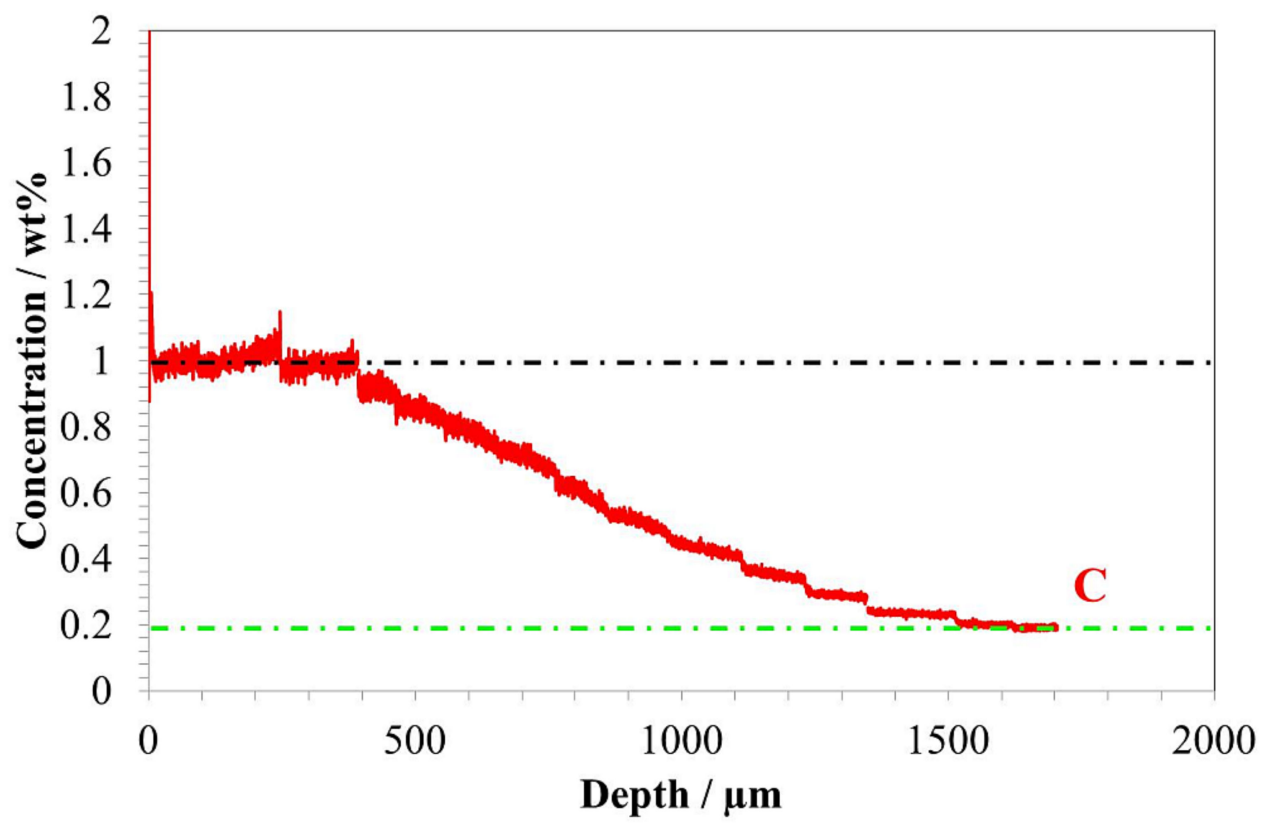

Figure 3. GD-OES concentration profile as a function of distance from the surface.

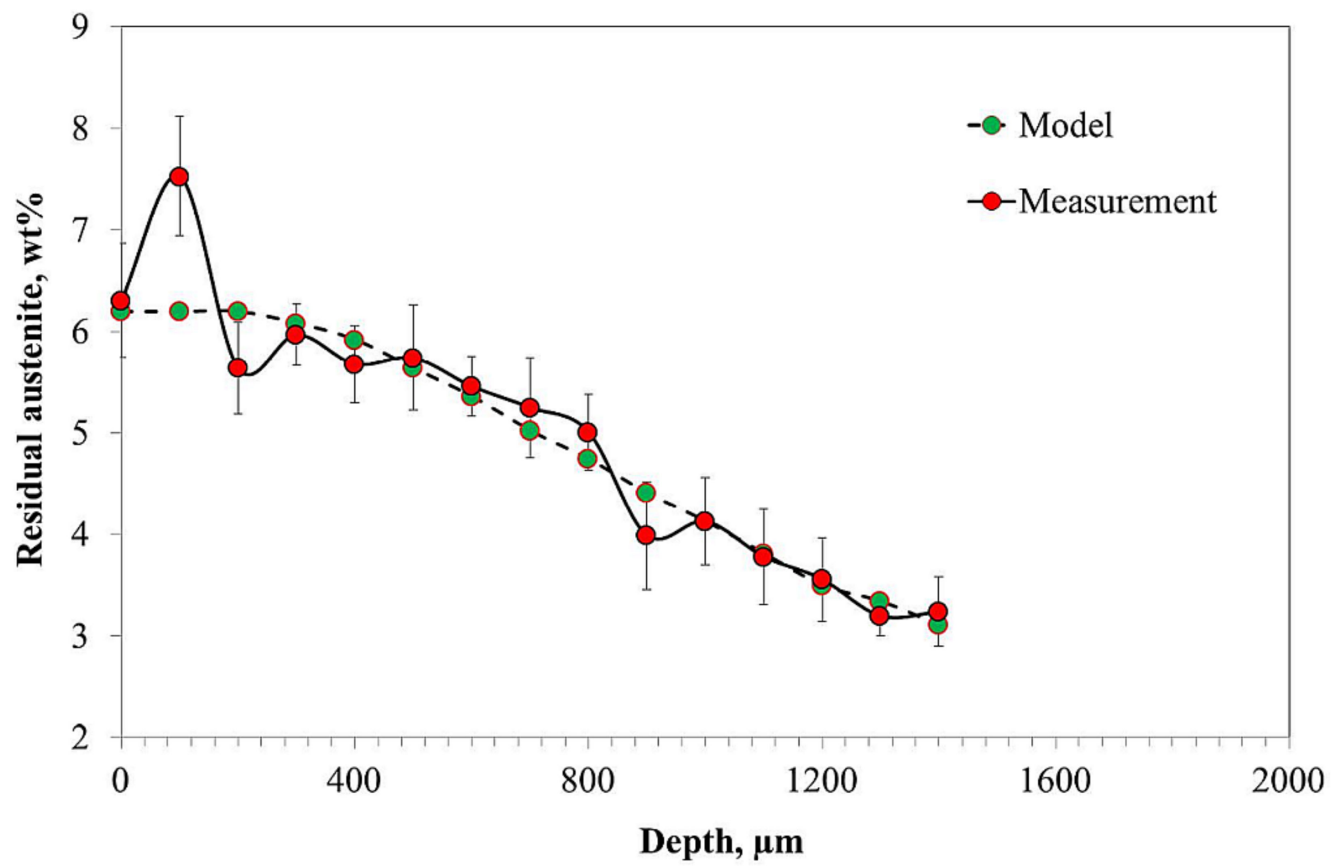

Figure 4. Measured and modeled residual austenite content profile as a function of distance from the surface expressed in weight percent.

Figure 5 shows the residual stress as a function of depth. Residual stresses were measured in the center of the sample in two directions $\left(\sigma_{x}\right.$ and $\left.\sigma_{y}\right)$. The values of residual stresses at each depth were averaged. It is clearly shown that the lowest compressive stresses are present in the subsurface region of the sample. The measured value of residual stress at this location is about $-100 \mathrm{MPa}$. As shown in Figure 5, an increase in depth results in a decrease of the value of measured stress (i.e., increase in compressive stress) to approximately $-375 \mathrm{MPa}$ at $800 \mu \mathrm{m}$. Beyond that depth, the function ascends. 


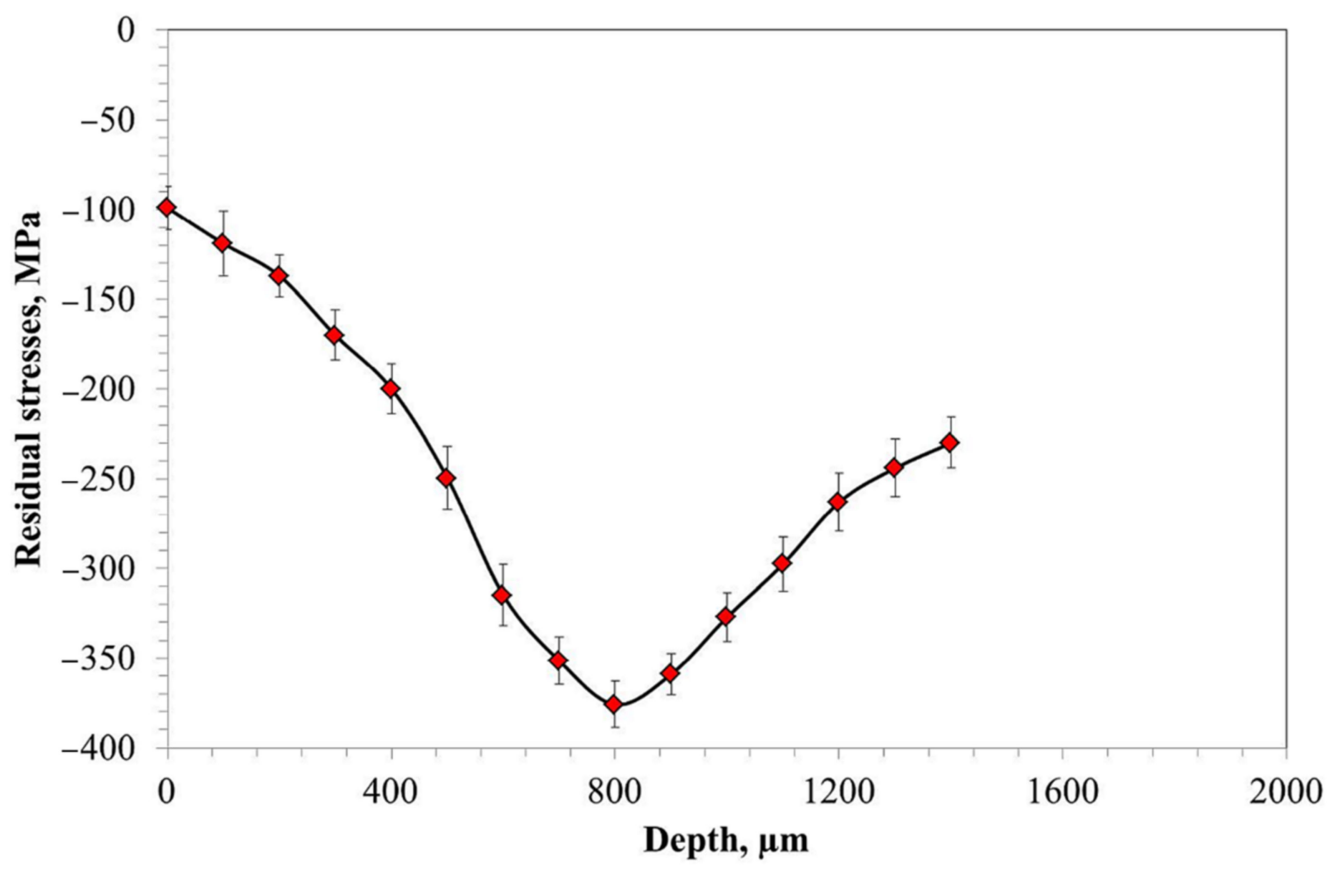

Figure 5. Residual stress profile as a function of distance from the surface.

The main objective of these studies was to observe the effects on the surface and carbon layer and to determine the relationship with other process parameters while also contributing to the larger picture of carburizing and quenching. The correlation between the composition profile of carbon, hardness profile, stress measurement, and microstructure was shown in this study. After case hardening, compressive residual stresses were found as expected. The global minimum was observed under the stress distribution. This situation arises when the two fronts of austenite-martensitic transformation occurred, Figure 6. It was found that there is dependence between the hardness and concentration profiles. This dependence for Pyrower53 steel can be expressed by linear function:

$$
\mathrm{H}=468 \mathrm{C}_{\mathrm{C}}+296
$$

where $\mathrm{H}$ is the hardness in $\mathrm{HV} 0.5$ and $\mathrm{C}_{\mathrm{C}}$ is the carbon concentration in $\mathrm{wt} \%$.

$\mathrm{R}$ squared fit parameter calculated for Equation (1) was equal to 0.98 . This function allows for determining the hardness profile from the concentration profile. A similar approximation can be proposed for the concentration profile and residual austenite profile relationship; in this case the function can be:

$$
\mathrm{RA}=3.91 \mathrm{C}_{\mathrm{C}}+2.29
$$

where $\mathrm{RA}$ is residual austenite in $\mathrm{wt} \%$ and $\mathrm{C}_{\mathrm{C}}$ is the carbon concentration in $\mathrm{wt} \%$.

$\mathrm{R}$ squared fit parameter calculated for Equation (2) was equal to 0.97 . These approximations allow for further determination of the process parameters. 


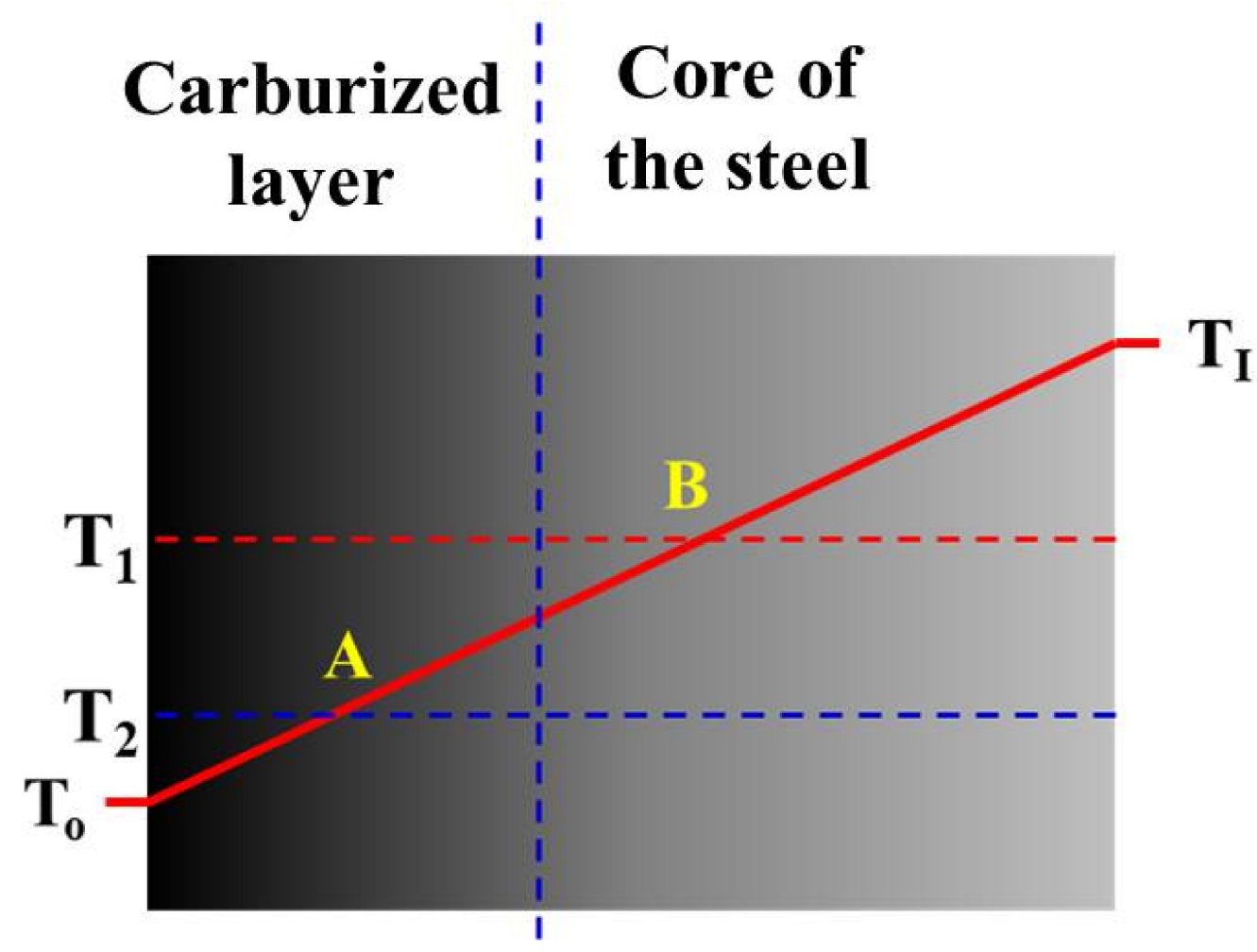

Figure 6. Schematic representation of temperature gradient in the subsurface region of carburized material. T1 and T2 specify the start of the austenite-martensitic transformation temperature; carbon content is shown by points A and B. The gray-shade gradient indicates variation of carbon content in the steel.

\section{Discussion}

The results obtained in the present work revealed a very good correlation between hardness (Figure 2), carbon content (Figure 3), and residual austenite content (Figure 4). Qualitatively, the plots shown follow the same trend, i.e., the highest values were obtained at the beginning of measurement, while increase in depth resulted in constant decrease of the measured values. Only a small variation between the hardness profile and carbon content depth profile was observed: at the beginning of hardness profile (approximately $100 \mu \mathrm{m}$ ) a slightly lower value of hardness was observed, about $730 \mathrm{HV}$; at a depth of 200 and $300 \mu \mathrm{m}$ a hardness of $760 \mathrm{HV}$ was observed. In parallel, no deviation in carbon content was observed in the region noted. The reason for this deviation between hardness profile and carbon profile follows. As observed in the image of microstructure of the material after carburizing, in the very outer part of the sample, formation of carbides is observed, while in the deeper part a uniform distribution of bright precipitates is observed (Figure 1). Thus, the main reason for the lower value of hardness is coarsening of precipitates. The reason why the GD-OES depth profile did not reveal lower carbon content (Figure 3) is that during GD-OES depth profiling, an area with a $4 \mathrm{~mm}$ diameter is sputtered, thus an average carbon content from the area noted is collected and measured. Therefore, for the GD-OES depth profiling, the size of precipitates does not play this detrimental role as in the case of hardness measurement. Considering this discussion, it can be concluded that the results of hardness and carbon concentration profile are in a very good agreement. It is clearly seen that the results of these two measurements are closely correlated. Thus, during mathematical modeling of the carburizing process, the concentration can be treated as interchangeable with the hardness of carbon in the steel. It would seem that the measured values of residual stress should follow the same trend. However, as shown in Figure 5, the residual stress distribution obeys a local minimum at a depth of $800 \mu \mathrm{m}$ (Figure 5). This minimum cannot be correlated with lower carbon residual austenite content. Therefore, 
there should be another factor determining this phenomenon. As stated by Yang et al. [28], the martensite transformation temperature (Ms) decreases with the decrease of carbon content in austenite, so that they are lower in the carburized layer and higher in the core. This situation is shown schematically in Figure 6.

Thus it is obvious that the temperature during the quenching process is lower at the carburized layer and higher in the core. Moreover, the carbon content is higher in the carburized layer. The austenite-martensitic transformation starts at lower temperature T2 (point A, Figure 6) in the carburized layer and becomes higher (point B, Figure 6) in the core of the steel. The consequence of this situation is that in order to obtain martensitic transformation in a carburized layer, it must be cooled to a lower temperature than in the core of the steel. This situation leads to the formation of two fronts of martensitic expansion, which consequently causes the occurrence of a high compressive stress zone (more negative values of residual stresses). The measured residual stress distribution (Figure 5) reveals that this zone is located at a depth between 600 and $1000 \mu \mathrm{m}$. Combining the latter and the GD-OES depth profile (Figure 3), it is observed that a high compressive stress zone is present in the material containing between about 0.8 and $0.4 \mathrm{wt} \%$ of carbon.

\section{Conclusions}

In the present work, Pyrowear53 steel was subjected to the impulse carburizing LPC process. After carburization, the material was quenched and tempered. Postprocessing analyses included the measurement of hardness, carbon content, residual austenite, and residual stresses. The results indicate the following conclusions:

- Carburizing, quenching, and tempering processes increased the hardness of Pyrowear53 from $400 \mathrm{HV}$ up to $750 \mathrm{HV}$ in the carburized layer.

- The hardness profile obtained correlates with the carbon content and residual austenite profiles.

- The results of residual stress measurement revealed the presence of a local extremum at a depth of about $800 \mu \mathrm{m}$ in the form of a zone showing the highest compressive stresses, despite no differences in hardness, carbon content, or residual austenite content.

- The occurrence of the extremum is explained by the formation of two fronts of martensite expansion, which result in the formation of a zone with higher compressive stresses at a depth between 600 and $1000 \mu \mathrm{m}$.

It was found that the presence of a zone with higher compressive stresses is observed in the material containing between 0.8 and $0.4 \mathrm{wt} \%$ carbon.

Author Contributions: Conceptualization, R.F. and B.W.; methodology, R.F. and B.W.; validation, R.F. and B.W.; formal analysis, R.F. and B.W.; investigation, B.K., K.O., K.G. and W.J.N.; data curation, B.K., K.O., K.G., W.J.N. and B.W.; writing—original draft preparation B.W., R.F. and W.J.N.; writingreview and editing, B.W., R.F. and W.J.N.; supervision, R.F. and B.W.; funding acquisition, R.F. and B.W. All authors have read and agreed to the published version of the manuscript.

Funding: This research was funded by National Center for Research and Development (Narodowe Centrum Badań i Rozwoju) under the TECHMATSTRATEG2/406725/1/NCBR/2020 program.

Institutional Review Board Statement: Not applicable.

Informed Consent Statement: Not applicable.

Data Availability Statement: The data are available from the corresponding author upon reasonable request.

Conflicts of Interest: The authors declare no conflict of interest.

\section{References}

1. Aramide, F.O.; Ibitoye, S.A.; Oladele, I.O.; Borode, J.O. Effects of carburization time and temperature on the mechanical properties of carburized mild steel, using activated carbon as carburizer. Mater. Res. 2009, 12, 483-487. [CrossRef]

2. Rajan, T.V.; Sharma, C.P.; Sharma, A. Heat Treatment Principles and Techniques; Prentice Hall: New Delhi, India, 1994. 
3. Denis, S. Coupled temperature stress, phase transformation calculation model numerical illustration of the internal stresses evolution during cooling of a eutectoid carbon steel cylinder. Metall. Trans. A 1987, 18, 1203-1287. [CrossRef]

4. Leblond, J. Mathematical modelling of transformation plasticity in steels II: Coupling with strain hardening phenomena. Int. J. Plast. 1989, 5, 573-591. [CrossRef]

5. Wang, K.F.; Chandrasekar, S.; Yang, H.T.Y. Experimental and computational study of the quenching of carbon steel. J. Manuf. Sci. Eng. 1997, 119, 257-265. [CrossRef]

6. Liu, C.; Xu, X.; Liu, Z. A FEM modeling of quenching and tempering and its application in industrial engineering. Finite Elem. Anal. Des. 2003, 39, 1053-1070. [CrossRef]

7. Xu, D.H.; Kuang, Z.B. A study on the distribution of residual stress due to surface induction hardening. Int. J. Eng. Mater. Technol. 1996, 118, 571-575. [CrossRef]

8. Shewmon, G.P. Diffusion in Solids; Mc Graw Hill: Tokyo, Japan, 1963.

9. Wojtyczka, A.; Iżowski, B. Microstructure and hardness of Pyrowear 53 steel after low-pressure vacuum carburizing at $921^{\circ} \mathrm{C}$. Adv. Manuf. Sci. Technol. 2020, 44, 109-112. [CrossRef]

10. Aerospace Material Specification AMS6308D. 2007. Available online: https://www.techstreet.com/standards/sae-ams6308d? product_id=1513574 (accessed on 10 May 2021).

11. Ferguson, B.; Li, Z.; Freborg, A. Modeling heat treatment of steel parts. Comput. Mater. Sci. 2005, 34, 274-281. [CrossRef]

12. Dean, S.W.; Banka, A.; Franklin, J.; Li, Z.; Ferguson, B.L.; Freborg, A.; Aronov, M. Improving control of a quenching process by coupling analysis methods. J. ASTM Int. 2009, 6. [CrossRef]

13. Bongartz, K.; Lupton, D.F.; Schuster, H. A model to predict carburization profiles in high temperature alloys. Metall. Trans. A 1980, 11, 1883-1893. [CrossRef]

14. Bongartz, K.; Schulten, R.; Quadakkers, W.J.; Nickel, H. A finite difference model describing carburization in high-temperature alloys. Corrosion 1986, 42, 390-397. [CrossRef]

15. Bongartz, K.; Quadakkers, W.J.; Schulten, R.; Nickel, H. A mathematical model describing carburization in multielement alloy system. Metall. Trans. 1989, 20, 1021-1028. [CrossRef]

16. Du, H.; Agren, J. Gaseous nitriding iron-Evaluation of diffusion data of nitrogen in of $\mathrm{N}$ in $\gamma^{\prime}$ and $\varepsilon$ phases. Int. J. Mater. Res. 1995, 86, 522-529. [CrossRef]

17. Dimitrov, V.I.; D’Haen, J.; Knuyt, G.; Quaeyhaegens, C.; Stals, L.M. Modeling of nitride layer formation during plasma nitriding of iron. Comp. Mat. Sci. 1999, 15, 22-34. [CrossRef]

18. Belmonte, T.; Gouné, M.; Michel, H. Numerical modeling of interstitial diffusion in binary systems. Application to iron nitriding. Mater. Sci. Eng. A 2001, 302, 246-257. [CrossRef]

19. Rozendaal, H.C.F.; Mittemeijer, E.J.; Colijn, P.F.; Schaaf, P.J. The development of nitrogen concentration profiles on nitriding iron. Met. Mater. Trans. A 1983, 14, 395-399. [CrossRef]

20. Cavaliere, P.; Zavarise, G.; Perillo, M. Modeling of the carburizing and nitriding processes. Comput. Mater. Sci. 2009, 46, 26-35. [CrossRef]

21. Keddam, M.; Djeghlal, M.; Barrallier, L. A simple diffusion model for the growth kinetics of $\gamma^{\prime}$ iron nitride on the pure iron substrate. Appl. Surf. Sci. 2005, 242, 369-374. [CrossRef]

22. Wierzba, B.; Romanowska, J.; Kubiak, K.; Sieniawski, J. The cyclic carburization process by bi-velocity method. High Temp. Mater. Process. 2015, 34. [CrossRef]

23. Bonarski, J.T. Measurement and Use of the Texture Stress Microstructure Characteristics in Materials Diagnostics; Institute of Metallurgy and Materials Science of the Polish Academy of Sciences: Cracow, Poland, 2013.

24. Skrzypek, S.J. New Possibilities of Measuring Macro Stress of Materials Using X-ray Diffraction in the Geometry of a Constant Angle of Incidence; AGH University of Science and Technology Press: Cracow, Poland, 2002.

25. Pfeifer, J.P.; Holzbrecher, H.; Quadakkers, W.J.; Breuer, U.; Speier, W. Quantitative analysis of oxide films on ODS-alloys using MCs + -SIMS and e-beam SNMS. Fresenius J. Anal. Chem. 1993, 346, 186-191. [CrossRef]

26. Quadakkers, W.J.; Elschner, A.; Speier, W.; Nickel, H. Composition and growth mechanisms of alumina scales on FeCrAl-based alloys determined by SNMS. Appl. Surf. Sci. 1991, 52, 271-287. [CrossRef]

27. Nowak, W.J. Characterization of oxidized Ni-based superalloys by GD-OES. J. Anal. At. Spectrom. 2017, 32, 1730-1738. [CrossRef]

28. Yang, Q.; Ren, J.; Gao, Y.; Li, Y.; Zhao, Y.; Yao, M. Effect of carburization on residual stress field of 20CrMnTi specimen and its numerical simulation. Mater. Sci. Eng. A 2005, 392, 240-247. [CrossRef] 